\title{
Prevalence of multiple sclerosis in north-east Scotland
}

\author{
DAVID I SHEPHERD, ALLAN W DOWNIE
}

\section{Summary and conclusions}

An epidemiological study of multiple sclerosis (MS) in north-east Scotland was carried out based on data correct on 1 December 1970. The prevalence of MS was 127 cases/100 000 population, which is greater than in any other surveyed area with a comparable population. The disease was not spread homogeneously within the region, and in one district one in 400 people was affected.

The geographical distributions of $M S$ and the presence of HLA antigens $A 3$ and $B 7$, which are associated with the disease, are remarkably similar, and the prevalence of B7 in north-east Scotland is higher than elsewhere. This may partly explain the high prevalence of MS in this area, but the essential additional environmental factor remains to be established.

\section{Introduction}

The geographical distribution of multiple sclerosis (MS) is unusual, the disease usually being more prevalent in temperate climates of high latitude, although some exceptions exist. ${ }^{1} \mathrm{~A}$ high-risk zone is one in which the prevalence is over 40/100 000 population and mortality rate from the disease over $1 / 100000$. $^{2}$ Among the epidemiological studies conducted in the $U K$, those carried out in Northern Ireland ${ }^{3}$ and Northumberland and Durham ${ }^{4}$ were particularly important, the first because it acted as a model and the second because of the size of the survey population. Those and other studies ${ }^{5-8}$ indicated that the UK was in the high-prevalence zone, but it has been shown ${ }^{9-11}$ that MS is more common in Orkney and Shetland than anywhere else in the world. We investigated the prevalence of MS in northeast Scotland according to where patients were living both at the time of the survey and at birth, and present here the results.

\section{Patients and methods}

The area we studied comprised the City of Aberdeen and counties of Aberdeen, Kincardine, Moray, and Banff, which is almost equivalent to the Grampian region. Until the advent of the North Sea industrial development the population was stable. The population at the 1971 Census was $440176,{ }^{12}$ of which $41^{\circ}$ lived in the ${ }^{\circ}$ City of Aberdeen. Almost the entire inpatient and outpatient hospital service for the area is located in Aberdeen, with only minimal referral elsewhere from the extreme periphery of the region.

After one of us (AWD) was appointed regional neurologist in 1965 a register was kept of all patients with MS. Most of the cases were ascertained from this. We examined the diagnostic index for Aberdeen's major hospitals, which extends to 1955, and further cases were located from the records of the neurosurgical department from 1948. All geriatric, psychiatric, and local general-practitioner hospitals in the region were visited, and cases obtained from the extensive surveillance of records were arranged into practices. Questionnaires were sent to

Department of Medicine, Aberdeen University, Aberdeen AB9 1AS DAVID I SHEPHERD, MD, MRCP, senior registrar in neurology (present address: Wessex Neurological Centre, Southampton General Hospital, Southampton $\mathrm{SO} 9 \mathrm{XY}$ )

ALLAN W DOWNIE, MB, FRCP, senior lecturer in neurology all GPs detailing patients thought to be under their care, ${ }^{1: 3}$ and they were asked to indicate which patients were alive and in the practice on 1 December 1970, which was chosen as prevalence day. They were also asked to note any other patients with MS, which contributed a further 73 patients to the final total. With minimal prompting a response was obtained from all the region's $250 \mathrm{GPs}$.

The diagnostic classification chosen was that of probable (group I), early probable and latent (group II), and possible MS (group III), in accordance with previous surveys. ${ }^{14}{ }^{15}$ Seventy-seven per cent of the patients were examined personally. In the remainder the information in the medical records was sufficient to permit classification. Patients were either allocated to one of the three diagnostic categories or rejected. Those who were rejected included patients with only retrobulbar neuritis or with other disease, those who had died before prevalence day, and those living outside the study area.

Geographical units-Scottish counties are subdivided into administrative "districts," which contain civil parishes. The four major cities are divided into wards. The population of each district or ward varies considerably, but usually exceeds 10000 . For this study north-eas Scotland was divided into 28 geographical units of about the same population size, adjacent districts being combined when necessary. We used the population figures from the 1971 Census $^{12}$ for area of residence on prevalence day and the 1921 Census figures ${ }^{16}$ for area of birthplace, since the mean age of all patients on prevalence day was $48 \cdot 2$ years. Because of changes in ward boundaries between 1921 and 1971 Aberdeen City was regarded as a single unit in assessing prevalence by area of birthplace. All other areas were the same for both residence on prevalence day and birthplace.

Statistical methods-To test the significance of the prevalence of MS by area we calculated the cumulative $\gamma^{2}$ (equals $=(\mathrm{O}-\mathrm{E})^{2} / \mathrm{E}$ where $\mathrm{O}$ is the observed and $\mathrm{E}$ the expected number of cases in each area). ${ }^{17}{ }^{18}$ For cell sizes 5-25 Yates's correction was applied. Kurtzke ${ }^{19}$ accepted that for any given area $(\mathrm{O}-\mathrm{E})^{2} / \mathrm{E}$ gives an "approximate" $\chi^{2}$ value $\left(\gamma^{2} \mathrm{a}\right)$. A $\chi^{2} \mathrm{a}=3.84$ for one degree of freedom represents $\mathrm{P}<0.05$ and thus for any given area shows a significantly high or low prevalence. Such a prevalence is almost certainly outside $75-125^{\circ}{ }_{0}$ of the mean prevalence in the whole region under study.

\section{Results}

On prevalence day 557 patients with MS were living in north-east Scotland. The overall prevalence was $127 / 100000$ population; in groups I and II the prevalence was 105/100 000 (table I). The ratio of females to males was $1 \cdot 6: 1$. The mean age at onset of MS in all patients was 34.2 years (range 10-61 years), with only a minimal difference between men and women ( $34 \cdot 4$ and $34 \cdot 0$ years respectively).

TABLE I-Prevalence of $M S$ in north-east Scotland according to group and sex

\begin{tabular}{|c|c|c|c|c|}
\hline & & & $\begin{array}{l}\text { No of patients } \\
\text { with MS }\end{array}$ & $\underset{\text { population* }}{\text { Prevalence } / 1000}$ \\
\hline $\begin{array}{l}\text { Group I ... } \\
\text { Groups I and II } \\
\text { All groups.. } \\
\text { All men } . \\
\text { All women }\end{array}$ & $\begin{array}{l}\because \\
\because \\
\because \\
\cdots\end{array}$ & $\begin{array}{l}\ldots \\
\cdots \\
\cdots\end{array}$ & $\begin{array}{l}310 \\
464 \\
557 \\
215 \\
342\end{array}$ & $\begin{array}{l}70 \\
105 \\
127 \\
102 \\
149\end{array}$ \\
\hline
\end{tabular}

*Population in $1971^{12}$ was 440176 : women 229 926, men 210250.

The mean age at onset in group I (31.8 years) was significantly less than that in all patients $(t=2.94, \mathrm{P}<0.01)$, and the mean in group III (38.8 years) was significantly greater than that in all patients $(t=5.27$ $\mathrm{P}<0.001)$. The mean age of all patients on prevalence day was $48 \cdot 2$ years (range 12-84), the mean ages by sex being identical. The mean duration of MS on prevalence day was 14.4 years, but $28 \cdot 7^{\circ}{ }_{0}$ of the patients had had the disease for over 20 and $11.5^{\circ} \%$ for over 30 years. The longest recorded duration was 57 years.

Prevalence by area of residence on 1 December 1970-The prevalences 
of MS in the 28 areas (table II) showed a distribution highly significantly different from that expected. A \%"a above 3.84 was obtained in three areas with prevalences above the mean and four with prevalences below. The greatest prevalence, $250 \cdot 7 / 100000$, occurred in area 16 in rural Aberdeenshire (fig 1). In the City of Aberdeen (fig 2) three adjacent "West End" wards (areas 7, 8, and 10) had rates more than $25^{\prime \prime}$ " above the mean for the whole region. This may well have been related to social class, since $45^{\circ}$ " of the patients from these three wards who could be classified according to occupation belonged to social classes I and II compared with an expected $23^{\prime \prime}$ "in the general population. ${ }^{21}$ The great prevalence recorded in area 4 was due to the preponderance of women patients ( 17 out of 23 , table II) rather than to any social class bias.

TABLE II-Prevalence of MS by area in which patients were living on 1 December 1970

\begin{tabular}{|c|c|c|c|c|c|}
\hline $\begin{array}{l}\text { Area } \\
\text { No }\end{array}$ & Population* & $\begin{array}{c}\text { No of } \\
\text { patients } \\
\text { with MS }\end{array}$ & $\begin{array}{c}\text { Expected } \\
\text { No of } \\
\text { patients }\end{array}$ & $\begin{array}{l}\text { Prevalence } \\
100000 \\
\text { population }\end{array}$ & $\%^{\prime}$ \\
\hline $\begin{array}{r}1 \\
2 \\
3 \\
4 \\
5 \\
6 \\
7 \\
8 \\
9 \\
10 \\
11 \\
12 \\
13 \\
14 \\
15 \\
16 \\
17 \\
18 \\
19 \\
20 \\
21 \\
22 \\
23 \\
24 \\
25 \\
26 \\
27 \\
28\end{array}$ & $\begin{array}{rr}9 & 623 \\
9 & 923 \\
18 & 121 \\
11 & 768 \\
17 & 392 \\
21 & 439 \\
15 & 748 \\
14507 \\
11 & 160 \\
16 & 248 \\
19 & 875 \\
15 & 349 \\
14 & 160 \\
10 & 606 \\
20 & 415 \\
10 & 768 \\
17027 \\
14 & 635 \\
14 & 220 \\
36 & 130 \\
15 & 242 \\
16 & 537 \\
11 & 724 \\
11 & 913 \\
14 & 146 \\
20 & 050 \\
16 & 343 \\
15 & 107\end{array}$ & $\begin{array}{r}13 \\
8 \\
11 \\
23 \\
20 \\
15 \\
29 \\
27 \\
17 \\
27 \\
22 \\
18 \\
13 \\
19 \\
16 \\
27 \\
20 \\
18 \\
24 \\
50 \\
22 \\
21 \\
19 \\
18 \\
9 \\
25 \\
19 \\
7\end{array}$ & $\begin{array}{l}12 \cdot 2 \\
12 \cdot 7 \\
22 \cdot 9 \\
14 \cdot 9 \\
22 \cdot 0 \\
27 \cdot 1 \\
19 \cdot 9 \\
18 \cdot 4 \\
14 \cdot 1 \\
20 \cdot 6 \\
25 \cdot 2 \\
19 \cdot 4 \\
17 \cdot 9 \\
13 \cdot 4 \\
25 \cdot 8 \\
13 \cdot 6 \\
21 \cdot 5 \\
18 \cdot 5 \\
18 \cdot 0 \\
45 \cdot 7 \\
19 \cdot 3 \\
20 \cdot 9 \\
14 \cdot 8 \\
15 \cdot 1 \\
17 \cdot 9 \\
25 \cdot 4 \\
20 \cdot 7 \\
19 \cdot 1\end{array}$ & $\begin{array}{c}135 \cdot 1 \\
80 \cdot 6 \\
60 \cdot 7 \\
195 \cdot 4^{\dagger} \\
115 \cdot 0 \\
70 \cdot 0 \\
184 \cdot 2+ \\
186 \cdot 1^{\dagger} \\
152 \cdot 3 \\
166 \cdot 2^{+} \\
110 \cdot 7 \\
117 \cdot 3 \\
91 \cdot 8 \\
179 \cdot 1^{+} \\
78 \cdot 4 \\
250 \cdot 7^{+} \\
117 \cdot 5 \\
123 \cdot 0 \\
168 \cdot 8^{+} \\
138 \cdot 4 \\
144 \cdot 3 \\
127 \cdot 0 \\
162 \cdot 1^{+} \\
151 \cdot 1 \\
63 \cdot 6 \\
124 \cdot 7 \\
116 \cdot 3 \\
46 \cdot 3 \\
\end{array}$ & $\begin{array}{r}0.007 \\
1.445 \\
5.675 \\
3.877 \\
0 \cdot 102 \\
4.965 \\
4.631 \\
3.566 \\
0.409 \\
1.690 \\
0.289 \\
0.042 \\
1.082 \\
1.941 \\
3.352 \\
12.236 \\
0.047 \\
1.680 \\
0.404 \\
0.251 \\
0.008 \\
0.925 \\
0.381 \\
3.942 \\
0.070 \\
7.045\end{array}$ \\
\hline Total & $440 \quad 176$ & 557 & $557 \cdot 0$ & $126 \cdot 5$ & $60 \cdot 062$ \\
\hline
\end{tabular}

*Obtained from 1971 Census. ${ }^{12}+$ More than $25^{\circ} \circ$ above mean prevalence. $\mathrm{DF}=27 ; \mathrm{P}<0.001$

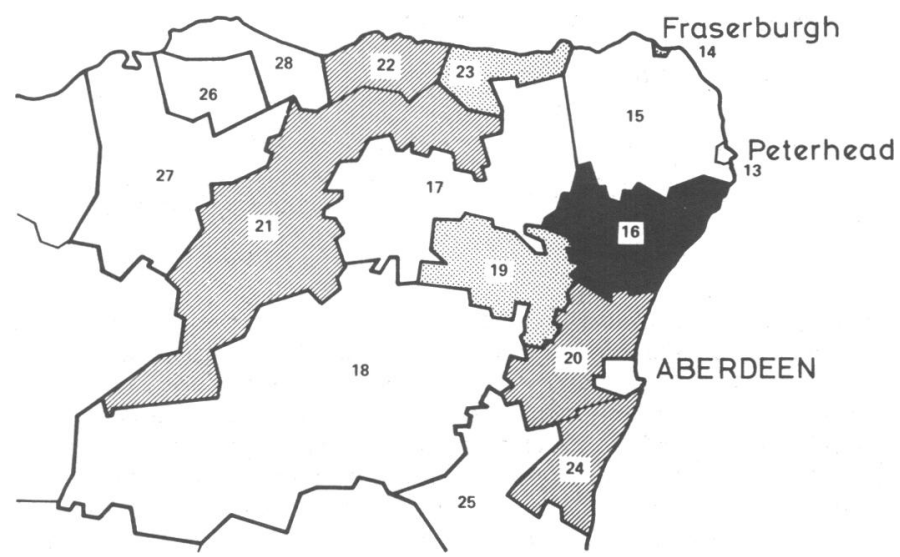

FIG 1-Prevalence of MS in north-east Scotland by area according to where patients were living on 1 December 1970 . $\square=$ Greater than $150 \%$ of mean

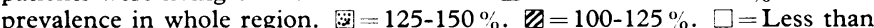
$100 \%$. (Mean prevalence in region $=126.5$ cases $/ 100000$ population.)

Prevalence by area of birthplace-Of the 557 patients, 439 were born in north-east Scotland, and further analysis was based on these. In 15 cases the place of birth was not known. Of the remaining 103 patients, four were born in Orkney and Shetland, 63 elsewhere in Scotland, 29 elsewhere in the UK, and seven abroad. With Aberdeen City considered as a single unit the distribution in all areas did not differ significantly from that expected (table III). Cases of MS occurred most often in the hinterland of Aberdeenshire, but prevalence by birthplace-as that by residence on prevalence day-was greatest in

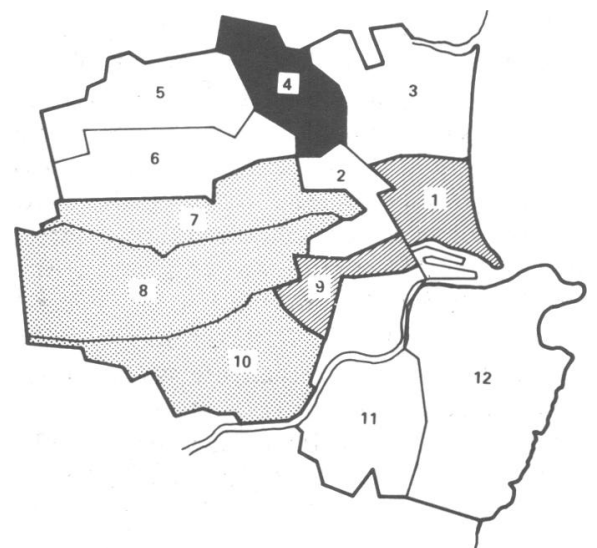

FIG 2-Prevalence of MS in City of Aberdeen according to area of residence on 1 December 1970. See fig 1 for key.

TABLE III-Prevalence of MS by area in which patients were born

\begin{tabular}{|c|c|c|c|c|c|}
\hline $\begin{array}{c}\text { Area } \\
\text { No }\end{array}$ & Population* & $\begin{array}{c}\text { No of } \\
\text { patients } \\
\text { with MS }\end{array}$ & $\begin{array}{l}\text { Expected } \\
\text { No of } \\
\text { patients }\end{array}$ & $\begin{array}{l}\text { Prevalence } \\
100000 \\
\text { population }\end{array}$ & $x^{2}$ \\
\hline $\begin{array}{c}1-12 \\
\text { (Aberdeen } \\
\text { City) } \\
13 \\
14 \\
15 \\
16 \\
17 \\
18 \\
19 \\
20 \\
21 \\
22 \\
23 \\
24 \\
25 \\
26 \\
27 \\
28\end{array}$ & $\begin{array}{rr}161 & 193 \\
13 & 126 \\
10 & 558 \\
28 & 340 \\
14 & 632 \\
24 & 192 \\
23 & 643 \\
16 & 124 \\
21 & 210 \\
22 & 286 \\
21 & 727 \\
13 & 285 \\
12 & 645 \\
17 & 132 \\
13 & 185 \\
15 & 528 \\
12 & 845\end{array}$ & $\begin{array}{r}146 \\
10 \\
10 \\
36 \\
24 \\
35 \\
25 \\
20 \\
20 \\
19 \\
17 \\
18 \\
12 \\
10 \\
17 \\
14 \\
6\end{array}$ & $\begin{array}{r}160 \cdot 2 \\
13 \cdot 1 \\
10 \cdot 5 \\
28 \cdot 2 \\
14 \cdot 5 \\
24 \cdot 0 \\
23 \cdot 5 \\
16 \cdot 0 \\
21 \cdot 1 \\
22 \cdot 2 \\
21 \cdot 6 \\
13 \cdot 2 \\
12 \cdot 6 \\
17 \cdot 0 \\
13 \cdot 1 \\
15 \cdot 4 \\
12 \cdot 8\end{array}$ & $\begin{array}{c}90 \cdot 6 \\
76 \cdot 2 \\
94 \cdot 7 \\
127 \cdot 0^{+} \\
164 \cdot 0^{+} \\
144 \cdot 7^{+} \\
105 \cdot 7 \\
124 \cdot 0 \\
94 \cdot 3 \\
85 \cdot 3 \\
78 \cdot 2 \\
135 \cdot 5^{\dagger} \\
94 \cdot 9 \\
58 \cdot 4 \\
128 \cdot 9^{+} \\
90 \cdot 2 \\
46 \cdot 7\end{array}$ & $\begin{array}{l}1.259 \\
0.516 \\
\\
2.157 \\
5.586 \\
4.594 \\
0.043 \\
0.766 \\
0.017 \\
0.328 \\
0.778 \\
1.401 \\
\\
2.485 \\
0.882 \\
0.053 \\
3.100\end{array}$ \\
\hline Total & 441651 & 439 & $439 \cdot 0$ & $99 \cdot 4$ & 23.965 \\
\hline
\end{tabular}

$* 1921$ Census. ${ }^{16}+$ More than $25^{\prime \prime}$, above mean prevalence.
$\mathrm{DF}=16 ; \mathrm{P}>0.05$.

area 16. Aberdeenshire (areas 13-20, see fig 1) had a significant excess of patients compared with the rest of the region $\left(\chi^{2}=8.551, P<0.01\right)$, but although Aberdeen City had fewer than expected, the deficit was not significant compared with the rest of north-east Scotland $\left(\chi^{2}=\right.$ $1 \cdot 981, \mathrm{P}<0 \cdot 1)$.

\section{Discussion}

In epidemiological studies in which information is requested from GPs the response is often incomplete and hence prevalence and incidence figures are underestimated. Such an approach would be more productive if each practice was equipped with a comprehensive diagnostic index, but until this happens it seems logical to present the GP with positive data concerning his patients. The value of contacting all GPs in a survey area has been questioned, ${ }^{713}$ but in the present study they contributed $13 \%$ of the total cases.

The overall prevalence of MS of $127 / 100000$ population in December 1970 indicates that the disease occurs more often in north-east Scotland than in any other surveyed area with a comparable population. This figure has been exceeded in only the Orkney and Shetland surveys ${ }^{1011}$ and studies of three population units of under 13000 in Finland and the USA. ${ }^{21-23}$ In larger populations prevalences above 100/100 000 have been found in Basle ${ }^{24}$ and in Gothenburg. ${ }^{25}$

The occurrence of MS in north-east Scotland shows a highly significant deviation from a random distribution. This has also been found in Sweden, Norway, Denmark, and Switzerland ${ }^{17} 26$ and Finland. ${ }^{27}$ In the present study the same area (area 16) had 
the greatest prevalence by current address and birthplace, but this was not due to any familial aggregation of cases. If environmental factors are implicated in the aetiology of MS then in this area they have been operating for many years. The area in which patients were living at the time of onset was not recorded since, whatever the aetiology of the disease, the important factors probably occur in early childhood, many years before clinical onset. ${ }^{28} 29$ Analysis of main area of residence in childhood was undertaken, but many patients had to be discarded because of multiple successive addresses in different areas. The distribution of MS among the patients remaining was almost identical with that by birthplace.

A deficit of cases in Aberdeen City was noted in the analysis by birthplace, but this was not significant. A highly significant deficit was recorded for births in Belfast compared with the rest of Northern Ireland, and the risk of developing MS was considered to be much greater if birth occurred outside Belfast. ${ }^{30}$ Similarly in Finland fewer cases than expected occurred in people born in Helsinki. ${ }^{31}$ These findings suggest that the risk of developing MS is less if birth occurs in a large urban centre. In contrast, however, no difference in urban-rural distribution was noted in north-east England, ${ }^{4}$ whereas in the US significantly more patients with MS had been born in towns compared with controls. ${ }^{32}$

Apparently there is a highly significant association between MS and the presence of HLA antigens A3 and B7, the mixedlymphocyte-culture determinant DW2, and certain B-lymphocyte alloantigens. ${ }^{33}{ }^{34}$ The world-wide occurrence of A3 and B7 in general populations follows a geographical pattern remarkably similar to the distribution of MS. ${ }^{29}{ }^{35} \mathrm{~B} 7$ has been found in $34.4 \%$ of a control population from north-east Scotland, ${ }^{36}$ a prevalence greater than that found in virtually any other control series. This may partly explain the prevalence of MS in northeast Scotland, but the essential additional environmental factor remains undisclosed.

This work formed part of the MD thesis of DIS and was supported by funds from the Maggie Whyte Bequest, Aberdeen University. Requests for reprints should be addressed to DIS.

\section{References}

${ }^{1}$ Kurland, L T, in Handbook of Clinical Neurology, ed P J Vinken and G W Bruyn, vol 9, p 63. Amsterdam, North Holland Publishing, 1970.
2 Acheson, E D, in Multiple Sclerosis; a Reappraisal, ed D McAlpine, C E Lumsden, and E D Acheson, p 42. Edinburgh, Churchill Livingstone, 1972

${ }^{3}$ Allison, R S, and Millar, J H D, Ulster Medical fournal, 1954, 23(2), 5.

4 Poskanzer, D C, Schapira, K, and Miller, H, fournal of Neurology, Neurosurgery and Psychiatry, 1963, 26, 368 .

5 Pratt, R T C, Compston, N D, and McAlpine, D, Brain, 1951, 74, 191. W

${ }^{6}$ Hargreaves, E R, Proceedings of the Royal Society of Medicine, 1961, 54, $ᄌ$ 209.

${ }^{7}$ Brewis, M, et al, Acta Neurologica Scandinavica, 1966, 42, suppl No 24, p 9. c

${ }^{8}$ Campbell, A M G, et al, Brain, 1950, 73, 52.

${ }^{9}$ Sutherland, J M, Brain, 1956, 79, 635.

${ }^{10} \mathrm{Fog}, \mathrm{M}$, and Hyllested, K, Acta Neurologica Scandinavica, 1966, 42, suppl No 19, p 9 .

${ }^{11}$ Poskanzer, D C, et al, Neurology, 1976, 26, No 6, pt 2, p 14.

12 General Register Office (Scotland), Census 1971 Scotland, Population $\overline{\bar{\omega}}$ Tables. Edinburgh, HMSO, 1974.

13 Stazio, A, Paddison, R M, and Kurland, L T, fournal of Chronic Diseases, 1967, 20, 311.

14 Alter, M, et al, World Neurology, 1960, 1, 55.

15 Broman, T, et al, Acta Neurologica Scandinavica, 1965, 41, suppl No 13, $\vec{\circ}$ p 543.

${ }^{16}$ General Registry Office, Scotland, Census 1961 (Scotland), County Reports. Edinburgh, HMSO, 1963.

${ }_{17}$ Kurtzke, J F, Acta Neurologica Scandinavica, 1966, 42, suppl No 19, p 91. O

${ }_{18}$ Kurtzke, J F, Acta Neurologica Scandinavica, 1967, 43, 257.

19 Kurtzke, J F, Fournal of Chronic Diseases, 1966, 19, 909.

20 General Registry Office, Scotland, Census 1961 (Scotland), vol VI o Occupation, Industry and Workplace, Part I Occupation Tables. Edinburgh, HMSO, 1966.

${ }^{21}$ Wikström, J, Acta Neurologica Scandinavica, 1975, 51, 173

22 Deacon, W E, et al, New England fournal of Medicine, 1959, 261, 1059.

${ }^{23}$ Eastman, R, Sheridan, J, and Poskanzer, D C, New England fournal of 윽 Medicine, 1973, 289, 793.

24 Georgi, F, and Hall, P, Acta Psychiatrica et Neurologica Scandinavica, ש 1960,35 , suppl No 147 , p 75

${ }^{25}$ Broman, T, et al, in Progress in Multiple Sclerosis, ed U Leibowitz, p 186. New York, Academic Press, 1972.

${ }^{26}$ Kurtzke, J F, Archives of Neurology, 1966, 14, 213

${ }^{27}$ Wikström, J, and Palo, J, Acta Neurologica Scandinavica, 1975, 51, 85.

${ }^{28}$ Millar, J H D, in Multiple Sclerosis. A Disease Acquired in Childhood. Springfield, Illinois, Thomas, 1971

${ }^{29}$ Alter, M, in Multiple Sclerosis. A Critical Conspectus, ed E J Field, p 35. Lancaster, MTP Press, 1977.

${ }^{30}$ Ashitey, G A, and Millar, J H D, Ulster Medical fournal, 1970, 39, 55.

31 Wikström, J, Myllylä, G, and Kivalo, E, Scandinavian fournal of Clinical and Laboratory Investigation, 1972, 29, suppl No 122, p 80.

32 Beebe, G W, et al, Neurology, 1967, 17, 1.

33 Winchester, R J, et al, Lancet, 1975, 2, 814

${ }^{34}$ Compston, D A S, Batchelor, J R, and McDonald, W I, Lancet, 1976, 2, 1261 .

${ }^{35}$ Shepherd, D I, MD thesis, University of Aberdeen, 1976.

${ }^{36}$ Lewis, H B M, personal communication, 1976.

(Accepted 19 May 1978)
ONE HUNDRED YEARS AGO Some weeks since, I was asked by a medical man of this town to a consultation, in a case of some cystic disease complicating pregnancy. The patient, aged 46 , had been married for about twenty years. She had borne many children, the last being born dead at full time and dropsical all over. When I saw her, she was seven months pregnant; the abdomen was very much distended, but symmetrical, and had the appearance of nine months' gestation. The umbilicus was considerably nearer the ensiform cartilage than the pubes, and was obliterated, if not pouched. Most marked fluctuation was obtainable over the whole of the front of the abdomen, as high as the sternum, but very little from flank to flank. The front of the abdomen was absolutely dull on percussion, dullness reaching upwards to about midway between the umbilicus and ensiform; but in each flank there was distinct resonance. The position of dullness remained the same on change of posture. Nothing could be made out on auscultation, beyond a very slight bruit over the right iliac fossa, synchronous with the maternal pulse. The lungs and heart were normal. The general condition of the patient was bad. She was feverish; pulse quick (120); and respiration hurried. There was marked prostration. There was no general or local oedema, nor could any history of such be obtained. Urine passed freely and voluntarily, was rather high-coloured, and free from albumen. The bowels had been opened freely after the exhibition of aperients. The patient said that the early months of pregnancy had been passed as usual; but for about four weeks (and especially the last week), the abdominal distension had increased very rapidly and caused a very great deal of pain.

The diagnosis appeared to lie between dropsy of the amnion and ovarian disease complicating pregnancy; and on taking into consideration the dropsy of the previous child, the very rapid distension of the abdomen, and its almost perfect symmetry, together with the fact that a few months before there was no sign of ovarian tumour present, I was led to diagnose the former. On making a vaginal examination, the os was low down, very soft and patulous; in fact, labour had commenced. This being so, the case passed out of my hands into that of the medical man in attendance. By him I am informed that labour went on rapidly. A dead dropsical child was born in about fourteen hours; and its birth was preceded by the escape of an immense amount of liquor amnii.

By the kindness of the medical man, I saw the case again, when the abdomen and pelvis were evidently perfectly free from the trace of any tumour, and beyond a little local peritonitis, the patient was doing well. She made a fair recovery. The explanation of the case appears to me to lie in some disease of the placenta, which prevented the due return of blood from the fœtus. The excess of amniotic fluid may have been derived from the fœtus, or, what is more probable, by transudation through the amniotic covering of the umbilical cord, or through the amniotic layer of the placenta. No syphilitic history could be made out. (British Medical fournal, 1878.) 